\title{
ENVIRONMENTAL TOXICANTS EVALUATION IN A MODERN MONITORING SYSTEM - ROMANIAN MONITOX NETWORK AREA
}

\section{Liliana Teodorof ${ }^{1,3}$, Adrian Burada ${ }^{1}$, Cristina Despina ${ }^{1}$, Daniela Seceleanu - Odor $^{1}$, Cristian Trifanov ${ }^{1}$, Antoaneta Ene ${ }^{2,3}$, Elena Zubcov ${ }^{3,4}$, Thomas Spanos ${ }^{3,5}$, Oleg Bogdevich ${ }^{3,6}$}

\author{
1. Danube Delta National Institute, 135 Babadag Street, Tulcea, Romania, \\ e-mail: liliana.teodorof@ddni.ro \\ 2."Dunarea de Jos" University of Galati, Faculty of Sciences and Environment, 47 Domneasca \\ Street, 800008 Galati, Romania, \\ 3. INPOLDE interdisciplinary research network, Dunarea de Jos University of Galati, 111 Do- \\ neasca St., Galati, Romania \\ 4. Institute of Zoology, Chisinau, Republic of Moldova \\ 5. International Hellenic University, Kavala, Greece \\ ${ }^{6 .}$ Institute of Geology and Seismology, Chisinau, Republic of Moldova
}

\begin{abstract}
In this paper a class consisting of 8 environmental toxicants were selected to assess Danube River water quality between Calarasi-Silistra sector until the river flow into the Black Sea, the Romanian Monitox Network Area. A comprehnsive comparison between 2 years of investigations in terms of nutrients contribution, such as different forms of nitrogen (ammonium nitrogen (N-NH4+), nitrite nitrogen (N-NO2-), nitrate nitrogen (N-NO3-), organic nitrogen, total nitrogen (TN)) and phosphorus (orthophosphate phosphorus (P-PO4 -3), total phosphorus (TP)), was made in order to provide information on the spatial and temporal variations of this river water quality. Sampling was performed according to European standards and quantitatively analysed using molecular spectrophotometry using UV VIS spectrophotometer Perkin Elmer Lambda 650S. The obtained results showed differences in nitrite nitrogen loads in surface water samples with higher values in the samples collected from the sampling points situated at the mouths of the Danube River into the Black Sea in 2020. Regarding quality classes, the surface waters were generally framed, in good quality class. The nutrients concentrations, combined in CCME WQI index, give an overview on surface water quality assessement in Romanian Monitox Network Area, with a good quality of Lower Danube (Constanta in 2019 and 2020) and fair quality of Danube Delta in 2020, but very closed to good quality.
\end{abstract}

\section{Introduction}

At the end of a $2860 \mathrm{~km}$ journey from its spring in the Black Forest Mountains, more precisely from Donaueschingen in Germany, to Pontus Euxinus (Black Sea), the Danube has been building, for over 12000 years by now, one of the most characteristic and beautiful deltas in Europe and even across the world [2].

For all its ranking second in size in Europe (after the Volga delta) and 20nd in the world, the Danube Delta's amazing landscape and fauna, birds in particular, represent a great scientific attraction, actually a study laboratory on the formation of deltaic, touristic and economic (natural renewable resources) ecosystems [2].

The Delta area is estimated at $4180 \mathrm{~km} 2,84 \%$ of which $(3510 \mathrm{~km} 2)$ lies on Romanian soil teritorry, between the three main Danube arms: Sfantu Gheorghe, Sulina and Chilia, listed in decreasing age [2]. Referring to the Black Sea " 0 " level, 20,5\% of the Delta area lies below this point and $79,5 \%$ above it. The greatest extension $(54,5 \%)$ has the territory comprised between 
0 and 1 meter high [2].

At European legislative level, there are concerns for improving the quality of surface waters in European Directives. Romania implements these directives (Annex P5.1.)

According to EU Water Framework Directive ecological status is an expression of the quality of the structure and functioning of aquatic ecosystems associated with surface waters. Furthermore, the WFD provides a selection of the most relevant quality elements for the classification of ecological status. Water Framework Directive established 5 quality classes color-coded, for surface waters (very good - blue, good - green, moderate - yellow, poor - orange, bad - red). For chemical indicators, all the concentrations values were reported to the Romanian Order 161/ 2006 which is the transposed of Water Framework Directive into Romanian Legislation.

The classification into the quality classes was made in accordance with Romanian Order $161 / 2006$, regarding the classification of surface water quality to determine the ecological status of water bodies, Table no. 6, Elements and biological quality standards, chemical and physical-chemical for setting ecological status of surface waters, Annex C, Elements and chemical, physical-chemical quality standards in water.

In the last years, many quality indexes were developed, integrating different physical-chemical indicators. Such an index is Canadian Council of Ministers of Environment Water Quality Index. This index takes into account nutrients concentrations and it is a useful tool for water quality management, because a single value describes the water quality.

\section{Materials and methods}

During the national trip, there were collected in 2019 and 2020, 50 surface waters samples for nutrients analysis.

For the dissolved forms (nitrite, nitrate, ammonia, orthophosphate) the surface water samples were stored at 2-5oC, for maximum 24 hours before analysis. For the analysis of total nitrogen, the samples were preserved on the field with $1 \mathrm{~mL} \mathrm{H} 2 \mathrm{SO} 4$ concentrate for $100 \mathrm{~mL}$ sample, store at $40 \mathrm{C}$ and analyzed in the laboratory. Determination of dissolved nutrients was made on filtered samples and total forms on unfiltered samples using UVVIS Lambda 10 PerkinElmer spectrophotometer, using ISO standards. The final results were expressed in $\mathrm{mg} / \mathrm{L}$. All the reagents have very good quality analytical grade. For quality assurance were made flow charts with the specific certified reference materials.

The ammonium concentration, expressed as N-NH4+, was determined at $655 \mathrm{~nm}$ by measuring the absorption of the blue compound formed by the reaction of ammonium ion with salicylate and hypochlorite ions in the presence of sodium nitroprusside, according with SR ISO 7150-1, Water quality, Determination of ammonium, Part 1.

Manual spectrometric method at UV-VIS Lambda 10 Perkin Elmer Spectrometer (SR ISO 7150-1 2001).

Nitrite (N-NO2-) was determined through formation of reddish purple azo dye color, produced at $\mathrm{pH} 2.0$ to 2.5 by coupling diazotized sulfanilamide with N-(1-naphthyl)- ethylenediamine dihydrochloride, according with SR EN 26667/ISO 6777/2002, Determination of nitrite, 
Molecular absorption spectrometric method, using the UVVIS Lambda 10 Perkin Elmer Spectrometer at $540 \mathrm{~nm}$. The analysis was made on filtered water (SR EN 26667/ISO 6777/2002).

The nitrate (N-NO3-) was determined according with SR ISO 7890-3:2000 - Water quality, Determination of nitrate, Part 3. Spectrometric method using sulfosalicylic acid, by spectrometric measurement of yellow compound absorbance formed by reaction of sulfosalicylic acid (formed by addition of sodium salicylate in the sample and sulfuric acid) with nitrate followed by treatment with alkaline solution, at UVVIS Lambda 10 Perkin Elmer Spectrometer (415 nm) (SR ISO 7890-3 2000). Determination of phosphorus content in surface waters was made according with SR EN 6878/2005, Water quality, Determination of phosphorus, Ammonium molybdate spectrometric method using UVVIS Lambda 10 Perkin Elmer Spectrometer at 880 $\mathrm{nm}$. For total phosphorus, the samples were treated on unfiltered water. Ammonium molybdate and potassium antimonyl tartrate react in acid medium with orthophosphate to form a heteropoly acid - phosphomolybdic acid - that is reduced to intensely colored molybdenum blue by ascorbic acid (SR EN 6878 2005). In order to evaluate the surface waters quality in an integrated index, it was computed CCME WQI - Canadian Council of Ministers of Environment Water Quality Index. The elements that underlie the calculation of this index are: scope (F1), frequency (F2), amplitude (F3), excursion [1,4]. With the computed values for this index, the surface water quality is classified in 5 classes, $0-44$ (poor quality), 45-64 marginal quality, 65- 79 fair quality, 80-94 good quality, 95-100 (excellent quality) [3,6].

\section{Results and discussions}

Since the end of 1970 until 1990, the nutrient emission from the anthropogenic sources along the Danube River had strongly influenced the amount of the nutrients accumulated into the Danube Delta's ecosystems [2,5].In surface waters, nutrients are represented by nitrogen and phosphorus in dissolved and total forms. In water bodies, ammonium is on the one hand a measure of the reduced inorganic form of nitrogen and in the other hand it consists of dissolved ammonia (NH3) and the ammonium ion (NH4+). In general, nitrogen is an essential plant nutrient and although ammonia is only a small component of the nitrogen cycle, it contributes to the trophic state of a water body. Water bodies eutrophication process consists in prolific algal growths, that have deleterious impacts on other aquatic life, drinking water supplies, and recreation and is determined by excess of ammonia concentrations. In surface waters, nitrite is an intermediate form of nitrogen compounds. It is an unstable form that is either rapidly oxidized to nitrate by nitrification process, or reduced to nitrogen gas by denitrification process. For plants, nitrite is a nutrient source. Nitrite boosts plants proliferation. For aquatic life, nitrite is toxic at relatively low concentrations. The most stable and oxidized form of nitrogen is nitrate. It results from the complete oxidation of all nitrogen compounds. Plants use nitrate as primary form of nutrients to stimulate plant growth. Excessive amounts of nitrogen may result in phytoplankton or macrophyte proliferations.

Total nitrogen is a sum of all forms of nitrogen (organic and inorganic). Nitrogen is an essential plant element and is often the limiting nutrient in marine waters. The importance of 
nitrogen in the aquatic environment varies according to the relative amounts of nitrogen forms presence, as ammonia, nitrite, nitrate or as organic nitrogen.

Phosphorus in surface waters is represented by inorganic and organic forms. The inorganic oxidized form of soluble phosphorus, is phosphate. This form of phosphorus is the most readily available for uptake during photosynthesis. High concentrations of orthophosphate generally occur in conjunction with algal blooms.

Total phosphorus is a measure of the inorganic oxidized form of soluble phosphorus. During photosynthesis, total phosphorus is available for uptake.

In this study, we evaluated from nutrients point of view, first, the quality classes for surface waters collected from the target areas of Monitox Network in Romanian sector and second to quantify the surface waters quality in terms of integrated indices.

According with Romanian legislation, it was established 5 quality classes, in accordance with EU Water Framework Directive, for each chemical indicator, with specific limits.

For ammonia nitrogen, in 2019, $93.75 \%$ of surface waters were framed into the first quality class (very good quality class) and $6.25 \%$ in second quality class (good quality class) and in 2020 all the surface waters had a very good quality class.

For nitrite nitrogen, the surface waters are framed in very good quality class $(15.62 \%$ $2019)$ good quality class $(81.25 \%$ - 2019, 60\% - 2020), and moderate quality class $(3.13 \%$ - 2019, 40\% -2020).

Table 1. CCME WQI values for surface waters of Romanian Monitox Network Area

\begin{tabular}{|c|c|c|c|}
\hline \multicolumn{2}{|c|}{$\begin{array}{c}\text { Sampling points } \\
2019\end{array}$} & \multicolumn{2}{|c|}{ CCME - WQI } \\
\hline \multirow{5}{*}{ 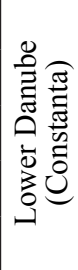 } & Fetesti & $\begin{array}{c}2020 \\
89.785\end{array}$ & 83.859 \\
\hline & Ostrov (bac pass) & 89.788 & 89.717 \\
\hline & Dunare veche Ostrov & 89.785 & 89.789 \\
\hline & Cernavoda bridge & 79.583 & 89.712 \\
\hline & Cernavoda Seimeni & 89.790 & 89.722 \\
\hline \multirow{10}{*}{ 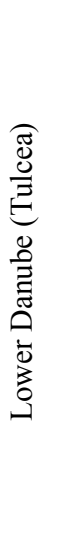 } & Braila upstream (mineral port) & 89.789 & 89.728 \\
\hline & Braila downstream (mineral port) & 89.789 & 89.719 \\
\hline & Galati downstream (mineral port) & 89.791 & 89.718 \\
\hline & Siret upstream & 89.757 & 78.957 \\
\hline & Siret upstream & 79.581 & 79.057 \\
\hline & Galati town downstream & 89.789 & 89.741 \\
\hline & Prut Giurgiulesti & 100.000 & 89.735 \\
\hline & Prut downstream & 79.580 & 89.722 \\
\hline & Reni downstream & 89.790 & 89.733 \\
\hline & Isaccea downstream & 89.790 & 89.751 \\
\hline
\end{tabular}




\begin{tabular}{|c|c|c|c|}
\hline \multirow{10}{*}{ 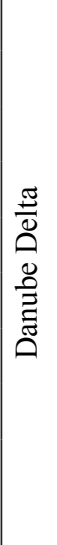 } & Ceatal Chilia & 89.771 & 89.738 \\
\hline & ChiliaVeche upstream & 89.793 & 78.937 \\
\hline & ChiliaVeche downstream & 89.791 & 78.947 \\
\hline & Musura bay (river mouth) & 89.787 & 79.310 \\
\hline & Sulina branch (river mouth) & 89.793 & 79.039 \\
\hline & Sfantu Gheorghe branch (river mouth) & 89.793 & 79.077 \\
\hline & Sf Gheorghe upstream & 89.792 & 79.064 \\
\hline & Sacalin & 89.789 & 79.313 \\
\hline & Ceatal Sf Gheorghe & 89.790 & 78.423 \\
\hline & Aval Izmail & 89.791 & 79.493 \\
\hline
\end{tabular}

For nitrate nitrogen, $50 \%$ of surface waters were framed in very good quality class in 2019 and $40 \%$ in 2020, and $50 \%$ in good quality class in 2019 and $60 \%$ in 2020.

Total nitrogen had values corresponding to the second quality class in $93.75 \%$ of surface waters in 2019, and 100\% in 2020, in Monitox network area and only $6.25 \%$ for third quality class in 2019 (Cernavodă bridge and Prut downstream).

For dissolved phosphorus, $84.37 \%$ of surface waters selected are framed in very good quality class in 2019 and $100 \%$ in 2020 , and $15.25 \%$ in second quality class in 2019 . For total phosphorus, $68.75 \%$ of samples are framed in very good quality class in 2019 and $80 \%$ in 2020 , and $31.25 \%$ in second quality class in 2019 and $20 \%$ in 2020 .

The obtained results showed differences in nitrite nitrogen loads in surface water samples with higher values in the samples collected from the sampling points situated at the mouths of the Danube River into the Black Sea in 2020. Concerning the total nitrogen levels in Danube waters, significant higher values were obtained in 2019, when the organic nitrogen fraction of the total nitrogen was much higher than the others nitrogen fractions, different from the data obtained in 2020, when the organic nitrogen and the sum of its inorganic forms from the total nitrogen had similar values. Regarding the phosphorus compounds, the concentrations determined in the two studied periods are not significantly different.

The computed values of CCME WQI index for surface waters sampled in Romanian Monitox Network Area, in 2019 and 2020, showed that in 2020, the surface waters quality decreased, comparing to 2019, due to nitrite concentrations. At 2019 level, 4\% of surface waters had an exccelent quality, $82 \%$ good quality and $12 \%$ fair quality. In $2020,56 \%$ of surface waters have good quality and 44\% fair quality. At integrative level, Lower Danube (Constanta) had a good quality in 2019 and 2020 and Danube Delta in 2020 had a fair quality (table 1).

Acknowledgements. The authors are thankful to the project with eMS code eMS BSB 27 "Black Sea Basin interdisciplinary cooperation network for sustainable joint monitoring of environmental toxicants migration, improved evaluation of ecological state and human health impact of harmful substances, and public exposure prevention - MONITOX”. The content of this publication is sole responsibility of the authors and does not reflect the views of the European Union. 


\section{Bibliography}

1. Bilgin A., Evaluation of surface water quality by using Canadian Council of Ministers of the Environment Water Quality Index (CCME WQI) method and discriminant analysis method: a case study Coruh River Basin, Environmental Monitoring and Assessement. 2018, 190:554. DOI: $10.1007 / \mathrm{s} 10661-018-6927-5$.

2. Gâștescu P., Știucă R., Delta Dunării Rezervația Biosferei, 2006, Ed. Dobrogea, 498 pg.

3. Kachroud M., Trolard F., Kefi M, Jebari S., Bourrié G., Water Quality Indices: challenges and application limits in the literature. Water. 2019, 11(2):361. DOI:10.3390/w11020361

4. Lumb A., Sharma T.C., Bibeault J.F., Klawunn P., A comparative study of USA and Canadian Water Quality Index models. Water Quality Expo Health, 2011, 3:203-216. DOI:10.1007/ s12403-011-0056-5.

5. Ostberg W., Buijse A. D., Coops H., Ibelings B. W., Menting G. A. M., StaraŞ M., Bogdan L., Constantinescu A., Hanganu J., Năvodaru I., Török L., Ecological gradients in the Danube Delta lakes. - Present state and man-induced changes. RIZA rapport 2000.015, The Netherland: 3-168.

6. Sutadian A.D., Muttil N., Yilmaz A., Perere B.J.C., Development of river water quality indices-a review. Environ Monit Assess. 2016, 188(58):2-29. DOI: 10.1007/s10661-015-5050-0. 